\title{
José Gaos y el giro de la filosofía iberoamericana
}

\author{
LUIS VILLORO \\ Instituto de Investigaciones Filosóficas \\ Universidad Nacional Autónoma de México
}

\begin{abstract}
REsumen: A mediados del siglo XX la filosofía en lengua española sufre un doble giro: por una parte, se transita hacia un mayor profesionalismo, por la otra, se busca adecuar el pensamiento filosófico a nuestra circunstancia. La obra de José Gaos puede presentarse como un ejemplo paradigmático de este giro de nuestra filosofía. En ella se hacen patentes los dilemas de la filosofía en lengua española que aún nos conciernen.
\end{abstract}

Palabras ClaVE: José Gaos, filosofía española, filosofía mexicana, filosofía latinoamericana

Conmemoramos en el 2000 los cien años del nacimiento de José Gaos. Este acto podría verse también como un recordatorio de los inicios de una empresa aún frágil: la construcción de una comunidad de lengua española en ambos lados del Atlántico. No sólo porque Gaos, transterrado entre España y México, podría presentarse como un emblema de una comunicación de pensamiento que arroja un fruto común a ambos países, sino por una razón que me parece más profunda.

A mediados del siglo xx el pensamiento filosófico en lengua española empieza a sufrir un giro. Podría intentar cernirlo por un par de características. En primer lugar, el tránsito a un mayor profesionalismo. Se tiende a abandonar el ensayo fácil y brillante, que da preferencia, a menudo, a la frase llamativa sobre el argumento, que no intenta desmarcarse del artículo literario o histórico; se intenta un mayor rigor en el razonamiento, sin temor a la sequedad; se procura una información cabal y una disciplina intelectual conformes a una educación profesional especializada.

En segundo lugar, ese sesgo se acompaña, me parece, de otro rasgo, no siempre coincidente con él: la preocupación por adecuar el pensamiento a la circunstancia. Se empieza a reflexionar sobre el sentido del pensamiento filosófico para la cultura en que se vive, se inquiere por su adecuación a la peculiar situación histórica; se pregunta por la posibilidad de que la reflexión filosófica no sea sólo imitación sino respuesta a problemas propios. Esos dos rasgos, búsqueda de un mayor rigor y de una creciente autenticidad, con los que se inicia un giro en nuestro pensamiento filosófico, son aún —en mi opinión - un ideal al que intenta acercarse la filosofía iberoamericana. 
Pues bien, vista a la distancia que da el tiempo, la obra de Gaos puede presentarse como un ejemplo paradigmático de ese giro en la filosofía de lengua española. En ella se vislumbran a la vez sus virtudes y sus limitaciones. Por eso, su recuerdo nos ayudará a comprender tanto las luces como las sombras de una empresa que aún es la nuestra.

Gaos concibió su labor, antes que nada, como la misión de un profesor. Consagró toda su energía intelectual, hasta el sacrificio, a la enseñanza. Aún sus escritos fueron pensados primero para la cátedra y quisieron guardar la forma de la lección oral. Sus clases y seminarios eran un modelo de información en la exposición, de rigor en el análisis de los textos, de claridad y precisión en su discusión. Por eso, no es exagerado sostener que, en México, la labor magisterial de Gaos fue el primer paso hacia el tratamiento profesional de la filosofía. Cierto que había habido antecedentes anunciadores de ese paso, pienso en Ortega, en España, y en Francisco Romero o Antonio Caso, por ejemplo, en América. Pero las obras de esos autores aún sucumbían a menudo al encanto del ensayismo fácil, cuajado de analogías brillantes. El tratamiento racional, escueto y preciso, sin concesiones, del pensamiento filosófico, empieza en mi país con la enseñanza de Gaos. De allí arrancan todos los vestigios que pudiera haber de razonamiento riguroso en los trabajos de las siguientes generaciones de filósofos mexicanos.

Pero ese sesgo hacia el profesionalismo filosófico se inicia con un estilo peculiar. En sus seminarios y cursos, y en gran parte de sus escritos, Gaos entendía la actividad filosófica como una explicación y esclarecimiento de los escritos de filósofos notables. Se trataba de desmenuzar un texto, de descubrir sus orígenes, de situarlo en su contexto e interpretar su sentido. No se preguntaba tanto por la verdad o falsedad de los problemas planteados sino por el significado y valor que tenían para su autor y su época. La reflexión tenía por objeto algo ya pensado por otro. Así, el rigor no se empleaba para ejercitar la razón en la solución de un problema, sino para dilucidar lo que el filósofo estudiado había pensado. El tratamiento profesional de la filosofía se entendía, ante todo, como comentario de lo que otros habían expuesto. ¿No es éste un rasgo que aún caracteriza, en gran medida, nuestra búsqueda de rigor filosófico? ¿No entendemos aún nuestra labor como comentario y discusión de un pensamiento ajeno antes que como ejercicio autónomo de nuestra propia razón?

Sólo en los últimos años de su vida, Gaos dio un gran salto. Ensayó un nuevo tipo de curso. Ya no consistía en el análisis de textos dados sino en la exposición de su reflexión personal, la que después daría lugar a sus dos mejores libros, De la filosofía y Del hombre. Al comentario de la razón ajena sucedía el despliegue de la razón propia. El resultado fue triste. Los alumnos prefirieron el Gaos comentador de Kant o de Heidegger al 
espectáculo incierto de un filósofo pensando por cuenta propia. Sólo cuatro de sus alumnos permanecimos hasta el final del curso.

Del segundo rasgo del giro en la filosofía en lengua española también es Gaos un ejemplo paradigmático. Discípulo de Ortega y Gasset, formado en el historicismo, Gaos partía de la creencia en el condicionamiento histórico de toda filosofía. Cada pensamiento responde a una perspectiva vital y cultural diversa. Esa diversidad le es esencial. Todo pensamiento tiene que atender a su circunstancia, no se entiende sin ella. Ese temple de ánimo se encontró en México con una corriente de dirección análoga. Antonio Caso, pero sobre todo Samuel Ramos, habían iniciado una búsqueda de las características propias de la cultura mexicana y se planteaban la pregunta por la adecuación del pensamiento a su circunstancia. Esa corriente formaba parte de un nacionalismo cultural que acompañó a la búsqueda de la propia identidad; era un reflejo de la revolución social que había tenido lugar años antes. El historicismo orteguiano de Gaos encontró una perfecta coincidencia con esa línea autóctona. El maestro español se convirtió entonces en un entusiasta promotor de los estudios sobre el pensamiento ligado a la circunstancia iberoamericana. Él mismo fue autor de artículos notables que destacan los rasgos comunes del pensamiento en lengua española y la unidad de destino de la cultura de los países de nuestra región. Fue una de las primeras voces en el despertar de un pensamiento que apunta al esclarecimiento de temas comunes a los países de nuestra cultura. Pero su labor principal fue el estímulo considerable a los estudios sobre el pensamiento latinoamericano, sobre todo el mexicano.

Esa labor formaba parte de una empresa que presenta dos facetas. Una es clara: en pocos años, en México, se redescubre una riqueza de pensamiento olvidada, se cobra conciencia de nuestras raíces, se empieza a plantear con seriedad, la pregunta por nuestra identidad. Y el trabajo de Gaos contribuye en gran medida a ese descubrimiento.

Pero la misma tarea presenta otra faceta no tan clara. En discípulos de Ramos y de Gaos, la búsqueda de la identidad deriva en un intento de encontrar lo peculiar de nuestro modo de ser y de nuestra cultura, aquello que nos distingue de los demás. Se llega a suponer que hay una realidad, un "ser" específico que distingue al latinoamericano, o más particularmente al mexicano, y que debe ser expresado en una filosofía peculiar. Una corriente llega a plantear la necesidad de crear una filosofía local, propia de nuestra región cultural. A la "filosofía del Manzanares" de la que llegó a hablar - tal vez con cierta ironía- Ortega, se suceden proyectos no menos peculiares como "la ontología del mexicano", "el modo de ser del panameño" o, simplemente, "la filosofía latinoamericana sin más". 
Gaos no cayó en esa actitud. Incluso formuló veladas críticas a esa tendencia. Sin embargo, no dejó de prohijarla. Y era comprensible, porque su filosofía personal tenía un rasgo fundamental que iba en un sentido análogo. En efecto, Gaos llevó hasta el final la interpretación de la filosofía como expresión de la vida del filósofo. Su historicismo, al llegar a ser radical, lo conducía un antropologismo filosófico. Porque al empujar a su término el condicionamiento de toda filosofía a su circunstancia, cada filósofo aparecía como una expresión de una vida humana históricamente irrepetible. Cada cultura, cada pensador incluso, tiene su propia filosofía, en la que se expresa vitalmente. La filosofía, antes que una vía para esclarecer problemas objetivos, es una expresión de la subjetividad. Gaos lleva hasta su término extremo esta concepción: la filosofía es, para él, una "confesión personal". Esa visión de la filosofía, aunque estuviera lejos de limitarla a un color local, era compatible con el intento de encontrar un modo de pensar propio, individualizado, que expresara el "ser" del pensador en situación. Más aún, yo diría que "la filosofía como confesión personal" y "la filosofía propia del ser latinoamericano" son dos posturas que llevan a su término coherente un historicismo radical.

La obra de José Gaos es un testigo privilegiado de un paso fundamental de la nueva filosofía de lengua española. En México al menos, nuestra marcha posterior a una filosofía que aspira a ser auténtica hubiera sido imposible sin ese primer paso. Sin embargo en una primera etapa el giro de que hablé se dio en un estilo que debía ser superado. La obra de Gaos es ejemplar de ese estilo. Pero puede verse también como un parteaguas. Si representa un momento extremo de una manera de comprender la filosofía, también vislumbra, en ocasiones, un nuevo estilo de filosofar.

Gaos es uno de los primeros pensadores en lengua española en plantear, dentro de los límites de su propia formación intelectual, algunos de los temas más vivos de la filosofía actual. Percibe la crisis del pensamiento moderno y se interroga con radicalismo por la función de la filosofía como actividad racional. "Filosofía de la filosofía" llamaba a esa reflexión. Lleva al cabo una crítica aguda, con rasgos originales, de la metafísica como forma de expresión, es decir como lenguaje. La interrogación sobre la validez de los enunciados filosóficos, sus esbozos de una filosofía de la expresión verbal, su insistencia en el valor del análisis conceptual son algunos rasgos de su obra que corresponden más al presente y al futuro inmediato que al pasado.

Por todo ello, estudiar la obra de Gaos es asomarnos a una radiografía de los primeros pasos en que evoluciona la nueva filosofía iberoamericana. En ella se hacen patentes los dilemas que aún nos conciernen. Para hacer posible una filosofía iberoamericana auténtica fue necesario el giro hacia 
una filosofía más profesional y rigurosa. Pero el rigor en el razonamiento ¿debe aplicarse exclusivamente al análisis y discusión de la filosofía creada por otros autores o debe ejercitarse en la actividad de la propia razón al tratar problemas objetivos? También era necesario acceder a una reflexión adaptada a los reclamos de nuestra circunstancia. Pero ¿debiera conducir a un pensamiento circunscrito a nuestras peculiaridades distintivas o a considerar desde nuestra propia perspectiva los problemas universales de la filosofía? La obra de Gaos se desarrolla en el corazón de esos dilemas.

Por eso, conmemorar su obra filosófica es también una ocasión de revivir las posibilidades y las dificultades que se abren en nuestra tarea actual: la construcción paulatina de una filosofía auténtica de lengua española.

Recibido: 28 de febrero de 2001

Aceptado: 13 de marzo de 2001 